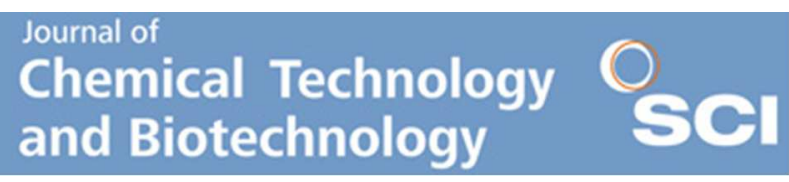

\title{
Capillary membrane bioreactor for abatement of low soluble compounds in waste gas
}

\begin{tabular}{|r|l|}
\hline Journal: & Journal of Chemical Technology \& Biotechnology \\
\hline Manuscript ID & Draft \\
\hline Wiley - Manuscript type: & Research Article \\
\hline Complete List of Authors: & $\begin{array}{l}\text { Morral, Eloi; Universitat Politècnica de Catalunya, Escola Politècnica } \\
\text { Superior d'Enginyeria de Manresa } \\
\text { Lao-Luque, Conxita; Universitat Politècnica de Catalunya, Escola Politècnica } \\
\text { Superior d'Enginyeria de Manresa } \\
\text { Gabriel, David; Universitat Autonoma Barcelona, Chemical Engineering } \\
\text { Gamisans, Xavier; Universitat Politècnica de Catalunya, Escola Politècnica } \\
\text { Superior d'Enginyeria de Manresa } \\
\text { Dorado, Antonio David; Universitat Politècnica de Catalunya, Escola } \\
\text { Politècnica Superior d'Enginyeria de Manresa }\end{array}$ \\
\hline Key Words: & $\begin{array}{l}\text { Membranes, Volatile Organic Compounds (VOCs), Waste Treatment and } \\
\text { Waste Minimisation, Environmental Biotechnology, Biofiltration of waste } \\
\text { gases, Bioprocesses }\end{array}$ \\
\hline \multicolumn{2}{|c}{} \\
\hline
\end{tabular}


2

3

4

5

6

7

8

9

10

11

12

13

14

15

16

17

\title{
Capillary membrane bioreactor for abatement of low soluble compounds in waste gas
}

\author{
$\underline{\text { Eloi Morral }^{\mathrm{a}} \text {; } \text { Conxita Lao-Luque }^{\mathrm{a}} \text {; David Gabriel }}{ }^{\mathrm{b}}$; Xavier Gamisans ${ }^{\mathrm{a}}$; Antonio \\ David Dorado ${ }^{\mathrm{a} *}$
}

${ }^{a}$ Escola Politècnica Superior d'Enginyeria de Manresa. Universitat Politècnica de Catalunya.

Av. Bases de Manresa, 61-73. 08242 Manresa (Spain)

${ }^{\mathrm{b}}$ GENOCOV Research Group, Department of Chemical, Biological and Environmental Engineering, Universitat Autònoma de Barcelona, 08193 Barcelona (Spain)

*Corresponding autor: (0034938777230).toni.dorado@upc.edu

\begin{abstract}
BACKGROUND: The removal of problematic volatile organic compounds (VOCs) from polluted gas (toluene, iso-octane and hexane) has been investigated in a membrane bioreactor (MBR) by adapting a commercial capillary microporous polypropylene membrane. The MBR performance was carried out under several operational conditions. The influence of the empty bed residence times (EBRT), the liquid velocity and the inlet concentration was evaluated.
\end{abstract}

RESULTS: For toluene, it was possible to treat higher loading rates than $1600 \mathrm{~g} \cdot \mathrm{m}^{-3} \cdot \mathrm{h}^{-1}$ with a maximum elimination capacity (EC) of $1309 \mathrm{~g} \cdot \mathrm{m}^{-3} \cdot \mathrm{h}^{-1}$, removal efficiencies (RE) of $\sim 80 \%$. However, iso-octane was poorly degraded as a single pollutant. Hexane presented lower EC values $\left(400 \mathrm{~g} \cdot \mathrm{m}^{-3} \cdot \mathrm{h}^{-1}\right)$ than toluene. The synergistic effect of hexane degradation in two different mixtures was also considered.

CONCLUSION: Our results demonstrate that a commercial membrane for wastewater treatment can be adapted for biological gas treatment, becoming a potential alternative 
1 to conventional biological treatment technologies, especially for pollutants with low

2 solubility.

3 Key Words: membrane bioreactor, VOCs, waste gas, hydrophobic compound

Nomenclature
VOCS
MBR
IL
EC
RE
EBRT
KL $_{\text {a }}$

TSS
Log Kow

Volatile Organic Compounds

Membrane BioReactor

Inlet Load

Elimination Capacity

Removal Efficiency

Empty Bet Residence Time

Volumetric overall mass transfer

coefficient

Total Suspended Solids

Octanol-water partition coefficients

4

5

6 1. INTRODUCTION

$7 \quad$ Volatile organic compounds are commonly found in waste gases from a wide

8 range of industrial processes. Several of these compounds are toxic air pollutants which

9 may cause serious health effects as well as environmental problems. Among them,

10 toluene, and n-hexane are enlisted in the EPA (United States Environmental Protection

11 Agency) hazardous air pollutants list $^{1}$. These two compounds are widely used as

12 solvents in industry such as paints, adhesives and fuel production. On the other hand,

13 iso-octane is a major component of gasoline and it is a very recalcitrant substrate.

14 Different physicochemical techniques such as absorption, adsorption and

15 thermal and catalytic oxidation have been used in order to reduce air pollutants. In the

16 last decades, biological gas treatment techniques such as bio(trickling)filtration,

17 bioscrubbing and membrane biofiltration have been widely studied and implemented as

18 alternatives for the traditional physical-chemical techniques ${ }^{2-4}$. Biological technologies 
1 present several advantages over conventional physicochemical ones, such as low

2 operating cost, low energy requirements, and the absence of waste products that require

3 further treatment or disposal. However, these biotechniques have some limitations like

4 large size reactors, hard control of moisture and $\mathrm{pH}$ (biofilters), channelling and,

5 specially, low removal efficiencies for highly hydrophobic pollutants (biotrickling

6 filters) $)^{5,6}$. Hydrophobicity involves poor transfer of the pollutants from the gaseous to

7 the liquid (and biofilm) phase where biodegradation occurs, as a result of a reduced

8 concentration gradient (driving force). In this sense, lower mass transfer rates means

9 higher gas residence times and higher bioreactor volumes. Due to their low solubility,

10 toluene, iso-octane and hexane have shown low elimination performances by traditional

11 biotechniques $^{7,8}$.

12 In membrane biological reactors (MBRs), two phases (gas and liquid) are

13 physically separated by the membrane. Pollutants dissolved in air pass through the

14 membrane by diffusion and are degraded by the microorganisms attached on the other

15 side where the culture medium is continuously recycled. The polymeric material of the

16 membrane is regarded as a mass transfer vector ${ }^{9}$ with the consequent improvement of

17 mass transfer of the poorly soluble compounds. In this regard, the use of membrane

18 bioreactor (MBR) for waste gas treatment is able to overcome these mass transfer

19 limitations due to the high permeability of some particular membranes for hydrophobic

20 pollutants $^{10}$. Since the membrane provides a physical separation between the liquid

21 phase and the gas phase, it is possible to change the liquid and gas flow independently,

22 without evaporation or overgrow problems and $\mathrm{pH}$ can be easily controlled. In MBR,

23 the membrane also serves as a support for the development of the microbial biofilm

24 responsible for pollutant biodegradation. 
1 The physical separation between the gas and liquid phase is also beneficial in 2 applications where direct contact of the air being treated with microorganisms is 3 undesirable ${ }^{11}$ such as hospitals or cleanrooms. Moreover, the polymeric membrane has 4 the capability to retain a certain amount of pollutant. The adsorbed pollutant can be used 5 by the microorganisms as a secondary substrate source. Thus, the system can be capable 6 to treat inlet flows with sudden pollutant variation, typically found in industrial 7 facilities, avoiding starvation periods ${ }^{12}$. This key parameter has been established in 8 several water treatment by MBR studies ${ }^{13,14}$. However, the adsorption capacity in MBR 9 for waste gas treatment remains unstudied.

10 Different MBR configurations have been described: hollow fibre (diameter $11<0.5 \mathrm{~mm})$, capillary $(0.5<$ diameter $<10 \mathrm{~mm})$, tubular (diameter $>10 \mathrm{~mm})$, flat sheet and 12 spiral-wounded ${ }^{15}$. For waste gas treatment, hollow fibres and flat sheet are the most 13 used configurations. Flat sheet membranes have a low fouling tendency and are easy to 14 clean, but they have a low packing density $\left(<100-400 \mathrm{~m}^{2} \mathrm{~m}^{-3}\right)$. On the contrary, hollow 15 fibre membranes have a very high packing density $\left(>30000 \mathrm{~m}^{2} \mathrm{~m}^{-3}\right)$, but have a very 16 high fouling tendency besides being difficult to clean properly ${ }^{16}$. Flat sheet membranes 17 have been widely studied for the gas waste abatement, although capillary membranes 18 could be a good alternative with a better performance ${ }^{17}$. Capillary membranes come to 19 be a balance between those two, they can afford higher packing density than flat sheet 20 avoiding the fouling problems that occurs in a hollow fibres bioreactor.

Despite MBR have been widely investigated for waste water treatment, it has

22 been sparsely studied in gas waste treatment. Therefore, unlike water treatment, the 23 implementation of the membranes for gas treatment at industrial scale needs much more 24 investigation to approach its implementation at industrial scale ${ }^{18}$. To the best of our 
1 knowledge, this is the first report on the hydrophobic VOCs long term operation by a 2 commercial capillary membrane, for both individual and mixture of VOCs.

3 In this work the biodegradation of three hydrophobic VOCs (toluene, iso-octane 4 and hexane) by a MBR was investigated. The MBR used is a commercial capillary 5 microporous polypropylene membrane module commonly used for wastewater 6 treatment. Toluene, n-hexane and iso-octane were selected according to their different 7 hydrophobicity in order to evaluate the influence of that factor. Their octanol-water 8 partition coefficients (Log Kow) are 2,7, 4,0 and 5,2 respectively. The effectiveness of 9 the system was studied under different operational conditions of empty bed residence 10 times, liquid velocities and inlet concentration. Moreover, experiments were performed 11 for both individual compounds and mixtures of different VOCs to emulate industrial 12 emissions, which usually contain more than one compound. The MBR adsorption 13 capability and the flow resistance were also investigated to evaluate the permeability 14 and feasibility for the biological technique.

15

\section{EXPERIMENTAL}

17

\subsection{Membrane}

A commercial module (Microdyn, Germany) consisting of 40 microporous membrane capillaries, usually used for the treatment of wastewater, was tested. The hydrophobic material of the membrane was polypropylene (PP) with an average pore size of $0.2 \mu \mathrm{m}$. The capillaries had an inner diameter of $1.8 \mathrm{~mm}$ and a length of $420 \mathrm{~mm}$ with total air volume 43 . The capillaries were sealed in a polyurethane module with an external diameter of $25 \mathrm{~mm}$ and a calculated shell volume of $206 \mathrm{~cm}^{3}$.

\subsection{Mineral medium and inoculum}


$1 \quad$ Mineral medium composition (per litre of water) was $\mathrm{KH}_{2} \mathrm{PO}_{4}(1 \mathrm{~g}), \mathrm{K}_{2} \mathrm{HPO}_{4}(1$

$2 \mathrm{~g}), \mathrm{NH}_{4} \mathrm{Cl}(1 \mathrm{~g}), \mathrm{NaCl}(1 \mathrm{~g}), \mathrm{MgSO}_{4}(0.02 \mathrm{~g}), \mathrm{CaCl}_{2}(0.02 \mathrm{~g})$ and trace elements $\left(1 \mathrm{~cm}^{3}\right)$;

3 the trace elements concentration was described elsewhere ${ }^{19}$. Activated sludge obtained

4 from an urban wastewater treatment plant (Salelles, Spain) was used for the inoculation

5 of the MBR, which was carried out by recirculating $1 \mathrm{dm}^{3}$ of the activated sludge, with

6 a biomass concentration of $4 \mathrm{~g} \cdot \mathrm{m}^{-3}$ (TSS), across the outer side of the membrane during

$7 \quad 72 \mathrm{~h}$. In this period biomass attachment was confirmed due to the decreasing of the 8 biomass concentration in the recirculation $\left(2 \mathrm{~g} \cdot \mathrm{m}^{-3}\right)(\mathrm{TSS})$.

\section{2.3. MBR set up}

Figure A.1 found in the supplementary data (appendix A) shows and schematic

11 of the plant constructed for the present study. The nutrients solution tank was placed in

12 a thermostatic bath at $30{ }^{\circ} \mathrm{C}$ under continuous stirring. The recirculation liquid flow rate

13 was adjusted to $1.20 \cdot 10^{-4} \mathrm{~m}^{3} \cdot \mathrm{h}^{-1}$ by a peristaltic pump (Cole Palmer, USA),

14 corresponding to a hydraulic retention time of $17 \mathrm{~h}$. The liquid phase was replaced

15 periodically with fresh solution to replenish nutrients and avoid accumulation of toxics

16 by-products.

17 The contaminated air stream was prepared by bubbling clean air in an impinger

18 filled with the target VOC. This stream was mixed with a secondary clean air stream in

19 a mixer camber to obtain the desired concentration in the final stream, which was

20 introduced to the reactor. Clean air flowrate was controlled by a flowmeter (Cole

21 Parmer, USA). The system had two sampling ports (inlet and outlet) that allowed

22 monitoring the inlet concentration $\left(\mathrm{C}_{\text {in }}\right)$ and the outlet concentration, $\left(\mathrm{C}_{\text {out }}\right)$. This data

23 was further used to calculate parameters such as the inlet load, IL $\left(\mathrm{g} \cdot \mathrm{m}^{-3} \cdot \mathrm{h}^{-1}\right)$;

24 elimination capacity, EC $\left(\mathrm{g} \cdot \mathrm{m}^{-3} \cdot \mathrm{h}^{-1}\right)$; and removal efficiency, RE $(\%)$. The outlet stream 
1 of the reactor was passed through a carbon filter to adsorb possible remaining pollutants

2 not biodegraded in the bioreactor.

$3 \quad$ 2.4. Analytical techniques

4

5 chromatography with a Perkin Elmer Clarus 400, USA instrument equipped with a

6 flame ionization detector (FID) and a capillary column (N65110C0, PerkinElmer,

7 USA). The gas carrier was helium at a flow rate of $1 \mathrm{~mL} \cdot \mathrm{min}^{-1}$. The injector and

8 detector temperature were $250^{\circ} \mathrm{C}$ and oven temperature was $200^{\circ} \mathrm{C}$. For gas mixtures,

9 the oven temperature set-up was $5 \mathrm{~min}$ at $50^{\circ} \mathrm{C}, 10^{\circ} \mathrm{C} \cdot \mathrm{min}^{-1}$ until $100^{\circ} \mathrm{C}$ and $5 \mathrm{~min}$ at

$10100^{\circ} \mathrm{C}$. The injection volume was $5 \mathrm{~cm}^{3}$ and was taken using a $5 \mathrm{~cm}^{3}$ syringe (Pressure-

11 Lok, USA). Oxygen and carbon dioxide concentrations were measured with an infrared

12 (IR) gas analyser (Maihak S710, Germany). Pressure drop was measured with a

13 differential pressure transmitter (Testo 506, Spain) for the gas phase and for the liquid

14 phase (Testo 512, Spain). In the liquid phase the dissolved oxygen (Oxical, Germany)

15 was adjusted at $7.5 \mathrm{~g} \cdot \mathrm{m}^{-3}$ by a constant air flow bubbling in the nutrient tank and the $\mathrm{pH}$

16 (Basic 20, Spain) at 6.5 by periodical addition of $\mathrm{NaOH}$ to offset the acidification of the

17 medium due to microorganisms activity. The biomass activity can be related with the

$18 \mathrm{CO}_{2}$ production inside the bioreactor, thus, an increase of the $\mathrm{CO}_{2}$ value in the outlet

19 steam indicates that the biomass was active and the biodegradation of the pollutant was

20 taking place.

\subsection{MBR abiotic characterization}

In order to determine the abiotic parameters of the MBR, mass transfer, sorption capacity and oxygen mass transfer were evaluated before inoculation. Sorption capacity was determined by frontal analysis methodology using toluene measurements at the 
1 inlet (tube side) and outlet (shell side) of the reactor as described elsewhere ${ }^{20}$. To adapt

2 this technique at the MBR characteristics, the polluted stream was introduced inside the

3 capillary. The outlet of the capillary module was sealed tightly. Thus, the total amount

4 of polluted gas was forced to pass through the membrane.

6 abiotic parameter studied. To evaluate the toluene mass transfer between gas and liquid

7 phases a test without biomass was carried out. For this purpose, the polluted stream

8 circulated inside the capillary membrane while water circulated along the shell side.

9 During this experiment several gas flows $\left(0.1-0.8 \mathrm{~m}^{3} \cdot \mathrm{h}^{-1}\right)$, pollutant concentration $(0.05-$

$\left.10 \quad 0.45 \mathrm{~g} \cdot \mathrm{m}^{-3}\right)$ and water flows $\left(1.4 \cdot 10^{-2}-7 \cdot 10^{-4} \mathrm{~m}^{3} \cdot \mathrm{h}^{-1}\right)$ were tested. The co-current and

11 counter-current gas and liquid flows configurations were also tested.

12

Finally, to determine the oxygen overall volumetric mass transfer coefficient $\left(\mathrm{K}_{\mathrm{L}} \mathrm{a}\right)$, a clean gas flow was circulated inside the capillary membrane while a deoxygenated water stream was circulated along the shell side. In order to deoxygenate the water a nitrogen flux was bubbled in the nutrient tank. The experiment was kept on until the equilibrium between the air and liquid phases was reached. To monitor the increase in dissolved oxygen concentration an oxygen sensor was put inside the nutrient tank. A dynamic mass balance for the liquid phase (Equation 1) allows to calculate the $\mathrm{K}_{\mathrm{L}} \mathrm{a}$ value.

$$
\frac{d S_{O_{2}}}{d t}=K_{L} a \cdot\left(S_{O_{2}}^{*}-S_{O_{2}}(t)\right)
$$

Where $d S_{O_{2}} \cdot \mathrm{dt}^{-1}$ is the dissolved oxygen (DO) rate, $S_{O_{2}}^{*}$ is the DO saturation concentration and $S_{\mathrm{O}_{2}}(\mathrm{t})$ is the DO concentration at the instant ' $\mathrm{t}$ '. A numerical solution algorithm based on Runge-Kutta methods was applied to compute the parameters in Eq. (1). All computations were performed in MATLAB R2016 using a curve fitting of 
1 experimental data. Parameters were estimated by minimizing the difference between the

2 experimental and predicted DO concentrations according to the following objective 3 function (2):

4

$$
F=\sqrt{\sum_{i=1}^{n}\left(D O_{\text {exp }}-D O_{\text {model }}\right)}
$$

5 Where $\mathrm{F}$ is the objective function to minimize, $\mathrm{n}$ is the number of experimental

6 measurements, $\mathrm{DO}_{\text {model }}$ is the simulated oxygen concentration $\left(\mathrm{g} / \mathrm{dm}^{3}\right)$ and $\mathrm{DO}_{\text {exp }}$ is the 7 experimentally measured oxygen concentration $\left(\mathrm{g} / \mathrm{dm}^{3}\right)$.

\section{$8 \quad 2.6 \mathrm{MBR}$ performance tests}

9 After abiotic tests, inoculation of the system was conducted. Table I summarizes 10 the tests performed with the MBR throughout the period studied. The membrane 11 bioreactor was operated for 7 months and experiments were divided into three stages. 12 The first stage experiment was started using toluene as unique pollutant. Elimination 13 capacity (EC) and the relationship with EBRT and efficiency percentage (RE\%) were 14 analysed over 70 days. Afterwards, the second stage was started using, firstly iso-octane 15 as unique pollutant and later, a mixture of toluene and iso-octane. When the second 16 stage was finished, the MBR was thoroughly washed, in order to remove the pollutants 17 previously adsorbed on the membrane, and inoculated again. Subsequently, the third 18 stage was started, firstly only with hexane over eighty days, the EC and the relationship 19 between RE\% and EBRT was determined and, then, the mixture performance of 20 hexane-toluene and hexane-methanol was tested. 


\section{3. RESULTS AND DISCUSSION}

$2 \quad 3.1$ MBR abiotic characterization

3

4

5 membrane. This parameter has been well established in several water treatment by

6 MBR studies ${ }^{13,14}$. However, the adsorption capacity of MBR for waste gas treatment

7 remains unstudied. To determinate the adsorption capacity, the polluted stream was

8 introduced inside the capillary while the outlet of the capillary module was sealed

9 tightly. Therefore, the total amount of polluted gas was forced to pass through the

10 membrane. The amount of pollutant adsorbed on the membrane was calculated by

11 frontal analysis methodology.

12

\section{$<$ FIGURE 1 $>$}

Fig 1 shows the amount of toluene adsorbed as a function of the inlet toluene concentration. As it can be seen, the amount of toluene adsorbed was linearly correlated with the toluene concentration in the inlet stream up to $1.5 \mathrm{~g} \cdot \mathrm{m}^{-3}$. However, beyond 1.7 $\mathrm{g} \cdot \mathrm{m}^{-3}$, the toluene adsorption remains almost constant regardless toluene inlet concentration. The maximum amount of toluene adsorbed on the membrane was 1.13 $\mathrm{g} \cdot \mathrm{m}^{-2}$. This value is quite similar to the value previously reported $\left(1.47 \mathrm{~g} \cdot \mathrm{m}^{-2}\right)$ by Juang et al. ${ }^{13}$. This type of isotherm curve is characteristic of interactions between a non-ionic aromatic solvent (toluene) and a hydrophobic polymer (polypropylene). This behavior could be for the high affinity of toluene for the membrane matrix, and the ability of the pollutant to diffuse into the crystalline regions of the polymer ${ }^{21}$.

A good adsorption capacity is a key parameter which can improve the robustness of the system when industrial emissions are treated. As an example, the system would 
1 be capable to adsorb toluene during $\sim 12 \mathrm{~h}$ under an IL $220 \mathrm{~g} \cdot \mathrm{m}^{-3} \cdot \mathrm{h}^{-1}\left(0.1 \mathrm{~g} \cdot \mathrm{m}^{-2} \cdot \mathrm{h}^{-1}\right)$. The

2 microorganisms can use this retained pollutant as a secondary source of substrate. So

3 the negative effects of starvation periods can be eliminated or reduced. It also can avoid

4 concentration fluctuations in the inlet stream that normally can be found in the

5 exhausted air from industrial facilities due to their daily and weekly rotation in the

6 production. Therefore, the membrane can be used as a buffer when fluctuations in the

7 gas inlet occurred and avoid starvation periods ${ }^{12,22}$.

8

\subsubsection{Mass transfer characterization}

In order to determine the maximum amount of pollutant that the system was capable to transfer from the gas side to the liquid side, a set of experiments using toluene as pollutant were carried out at several EBRT, IL and water flows. The polluted stream at different flows $\left(1 \cdot 10^{-2}-8 \cdot 10^{-2} \mathrm{~m}^{3} \cdot \mathrm{h}^{-1}\right)$ and different concentrations $\left(5 \cdot 10^{-2}\right.$ $4.5 \cdot 10^{-1} \mathrm{~g} \cdot \mathrm{m}^{-3}$ ) was forced to circulate inside the capillary membrane while water flow $\left(7 \cdot 10^{-4}-1.4 \cdot 10^{-2} \mathrm{~m}^{3} \cdot \mathrm{h}^{-1}\right)$ circulated along the shell side. Those configurations correspond to a gas linear velocity of $100-800 \mathrm{~m} \cdot \mathrm{h}^{-1}$ (tube side) and a water linear velocity of 35 $1.75 \mathrm{~m} \cdot \mathrm{h}^{-1}$ (shell side).

The maximum mass transfer, $226 \mathrm{~g} \cdot \mathrm{m}^{-3} \cdot \mathrm{h}^{-1}(\mathrm{RE} 26 \%),\left(0.1 \mathrm{~g} \cdot \mathrm{m}^{-2} \mathrm{~h}^{-1}\right)$, was obtained when the gas flow was $8 \cdot 10^{-2} \mathrm{~m}^{3} \cdot \mathrm{h}^{-1}$ and the liquid flow was counter-current pumped at $1.410^{-2} \mathrm{~m}^{3} \cdot \mathrm{h}^{-1}$. Working under the same conditions, except for the water flow rate which was reduced to $7 \cdot 10^{-4} \mathrm{~m}^{3} \cdot \mathrm{h}^{-1}$, the RE slightly decreases $(23 \%)$. This indicates that, in the range studied in the present work, the liquid flow rate has little influence on the system performance, when the reactor works at counter-current flows set-up. On the other hand, when the same operation conditions were tested using cocurrent flow an important reduction of the RE\% was observed. RE\% values decrease 
1 from $23 \%$ to $14 \%$ when liquid flowrates of $1.410^{-2} \mathrm{~m}^{3} \cdot \mathrm{h}^{-1}$ and $7 \cdot 10^{-4} \mathrm{~m}^{3} \cdot \mathrm{h}^{-1}$ were used,

2 respectively. Modelsky et al. $^{23}$ also observed an important reduction of the mass

3 transfer, between the gas side to the liquid side, when the liquid velocity was decreased

4 in a polypropylene capillary reactor working under co-current flows. Based on these

5 results co-current operation and a liquid flow rate of $7 \cdot 10^{-4} \mathrm{~m}^{3} \cdot \mathrm{h}^{-1}$ were used in the

6 biotics experiments to evaluate the performance of the MBR working at the more

7 unfavorable conditions and, thus, to evaluate the system improvement when the

8 bioreactor was inoculated.

9

\subsubsection{Determination of oxygen mass transfer}

In the MBR, VOCs are degraded aerobically; this means that $\mathrm{O}_{2}$ concentration in the liquid medium is a key parameter for proper operation of the system. To evaluate the membrane capability to supply $\mathrm{O}_{2}$, the volumetric mass transfer coefficient, $\mathrm{K}_{\mathrm{L}} \mathrm{a}$, was calculated. In order to determine the $\mathrm{K}_{\mathrm{L}} \mathrm{a}$ a clean gas flow was circulated inside the capillary membrane while a deoxygenated water stream was circulated along the shell side. The experiment was kept on until equilibrium between the air and liquid phases was reached. $\mathrm{K}_{\mathrm{L}}$ a values determined for the experiments were found to be in the range 2.75-3.25 $\mathrm{h}^{-1}$. These values are significantly lower than those reported in the literature for other kind of reactors $\left(3.6-180 \mathrm{~h}^{-1}\right.$ for a perforated plate, $360-1800 \mathrm{~h}^{-1}$ for a jetventuri and $54-108 \mathrm{~h}^{-1}$ for a venturi ejector ${ }^{24}$. However, one advantage when a MBR is used it is possible to create a bubbleless aeration system ${ }^{25}$. The absence of bubbles in the liquid side might improve the biomass grow.

In order to calculate the amount of oxygen transferred from the gas side to the liquid side through the membrane, the standard oxygen transfer rate (SOTR, $\mathrm{kg} \mathrm{O}_{2} \mathrm{~h}^{-1}$ ) was calculated according to equation 3 : 


$$
\operatorname{SOTR}=K_{L} a \cdot S_{O_{2}}^{*} \cdot V_{M}
$$

1 Where $\mathrm{K}_{\mathrm{L}} \mathrm{a}$ is the mass transfer coefficient $\mathrm{h}^{-1}, S_{O_{2}}^{*}$ is the dissolved oxygen 2 concentration at saturation, $\mathrm{kg} \cdot \mathrm{m}^{-3}$ and $\mathrm{V}_{\mathrm{M}}$ is the volume of the membrane, $\mathrm{m}^{3}$. In the 3 present work, a SOTR value of $1.2 \cdot 10^{-3} \mathrm{~g} \cdot \mathrm{h}^{-1}$ was obtained for a $\mathrm{K}_{\mathrm{L}}$ a of $3.25 \mathrm{~h}^{-1}$ (the 4 most favourable $\mathrm{K}_{\mathrm{L}} \mathrm{a}$ value obtained). Equation 4 shows the theoretical complete 5 biodegradation (mineralization) of toluene. Taking into account the reaction 6 stoichiometry, it has been estimated that an oxygen rate of $1.3 \cdot 10^{-2} \mathrm{~g} \cdot \mathrm{h}^{-1}$ would be 7 necessary to degrade an IL of $100 \mathrm{~g} \cdot \mathrm{m}^{-3} \cdot \mathrm{h}^{-1}$. Therefore, the maximum amount of $\mathrm{O}_{2}$ $8 \quad\left(1.2 \cdot 10^{-3} \mathrm{~g} \cdot \mathrm{h}^{-1}\right)$ that the system is capable to supply is ten times lower that the theoretical $9 \mathrm{O}_{2}$ amount needed. In order to improve the total amount of dissolved oxygen, a 10 secondary diffuser was introduced into the nutrient tank when the biotic tests were 11 carried out. Actually, this behaviour is similar to the observation reported by Kumar et $12 \mathrm{al}^{26}$ who observed an improvement of toluene rate consumption when oxygen is 13 supplied through both the membrane and the liquid phase.

$$
\mathrm{C}_{7} \mathrm{H}_{8}+9 \mathrm{O}_{2} \rightarrow 7 \mathrm{CO}_{2}+8 \mathrm{H}_{2} \mathrm{O}
$$

\section{$14 \quad 3.2$ Biotic performance}

\subsubsection{Study of toluene abatement}

After the abiotic experiments, the MBR was inoculated with a mixed

17 consortium. During the first 50 days of this research, only toluene was fed into the MBR 18 at an inlet concentration ranging from 200 to $5000 \mathrm{ppm}_{\mathrm{v}}$ at an EBRT of $60 \mathrm{~s}$ which 19 corresponded to IL from $43 \mathrm{~g} \cdot \mathrm{m}^{-3} \cdot \mathrm{h}^{-1}\left(2 \cdot 10^{-2} \mathrm{~g} \cdot \mathrm{m}^{-2} \cdot \mathrm{h}^{-1}\right)$ to $1600 \mathrm{~g} \cdot \mathrm{m}^{-3} \cdot \mathrm{h}^{-1}\left(7 \cdot 10^{-1} \mathrm{~g} \cdot \mathrm{m}^{-}\right.$

$20{ }^{2} \cdot h^{-1}$ ), respectively. This concentration could be highest that the typically values found 21 in industrial gas waste, however the aim of this work was studied the maximum 22 performance of the system. The performance of the reactor was determined by 
1 measuring the inlet and outlet toluene concentrations to calculate EC and RE. After day

250 , the inlet concentration was gradually decreased to $1000 \mathrm{ppm}_{\mathrm{v}}$, moment at which the

3 tests to determinate the relationship between the RE and EBRT was started (from day 460 to 70$)$.

5

6

7 seen the start-up period was quick, the RE quickly increased to around $90 \%$ after $72 \mathrm{~h}$

8 of operation. This behaviour is similar to the observation reported by Dorado et al. ${ }^{27}$,

9 who had used activated sludge obtained from the same urban wastewater treatment plant

$<$ FIGURE 2>

Fig 2 shows the EC and the RE of the system along the first 70 days. As can be that was used in the present work. As can be also observed, the maximum EC was 1300 $\mathrm{g} \cdot \mathrm{m}^{-3} \cdot \mathrm{h}^{-1}\left(6 \cdot 10^{-1} \mathrm{~g} \cdot \mathrm{m}^{-2} \cdot \mathrm{h}^{-1}\right)$ and values of RE obtained were always higher than $95 \%$ and sometimes even $100 \%$ in the inlet loading rate between $43 \mathrm{~g} \cdot \mathrm{m}^{-3} \cdot \mathrm{h}^{-1}-1300 \mathrm{~g} \cdot \mathrm{m}^{-3} \cdot \mathrm{h}^{-1}$. But, when the IL was higher than $1300 \mathrm{~g} \cdot \mathrm{m}^{-3} \cdot \mathrm{h}^{-1}$ a RE drop down to $80 \%$ was observed. On the other hand, when the relationship between EBRT and RE was studied an important decrease on the overall system performance at low EBRT was observed (from day 60 to 70$)$.

$<$ FIGURE $3 \mathrm{~A}$ and $3 \mathrm{~B}>$

EC values as function of IL are shown in Fig. 3A. In this figure, it is observed that values of RE obtained for inlet loading rate between 43 and $1200 \mathrm{~g} \cdot \mathrm{m}^{-3} \cdot \mathrm{h}^{-1}$ were higher than $95 \%$ and sometimes, $100 \%$. Over this IL value, the efficiency of the system decreased to $80 \%$. However, the EC remained almost constant and close to $1300 \mathrm{~g} \cdot \mathrm{m}^{-}$ ${ }^{3} \cdot \mathrm{h}^{-1}\left(0.6 \mathrm{~g} \cdot \mathrm{m}^{-2} \cdot \mathrm{h}^{-1}\right)$ regardless the increasing inlet concentration. This indicates that this value is the maximum EC that the system was capable to eliminate at an EBRT of 60 s. It's noteworthy that these EC values found in the present work are quite superior to those reported by some authors working under similar condition but with different 
1 configurations of bioreactors. For example, Zilli et al. ${ }^{28}$ reached an EC of $242 \mathrm{~g} \cdot \mathrm{m}^{-3} \cdot \mathrm{h}^{-1}$

2 (RE 24\%) when a biofilter was fed with an IL of $1000 \mathrm{~g} \cdot \mathrm{m}^{-3} \cdot \mathrm{h}^{-1}$ at EBRT of 28s.

3 Whereas Aizpuru et al. ${ }^{4}$ studied the biofilter performance at EBRT of 90s and an IL of $41700 \mathrm{~g} \cdot \mathrm{m}^{-3} \cdot \mathrm{h}^{-1}$, obtaining an EC of $290 \mathrm{~g} \cdot \mathrm{m}^{-3} \cdot \mathrm{h}^{-1}(\mathrm{RE} 17 \%)$. These promising results

5 obtained in the present study shown that MBR has a very high potential to be used for

6 the treatment of poorly soluble pollutants at very high loads. The higher EC obtained

7 here compared to traditional biofiltres configuration could be due to the fact that the

8 membrane constitutes a physical separation between the gas and the liquid phases.

9 Thus, the pollutant diffuses directly from the membrane to biofilm avoiding the

10 diffusion through water, limited step when hydrophobic compounds are treated.

To evaluate the relationship between RE and EBRT a constant inlet

12 concentration of $1000 \mathrm{ppm}_{\mathrm{v}}$ was used while the EBRT was decreased. The results

13 obtained during this stage are plotted in Fig 3B. The maximum RE of the system was

$1499 \%$ at the EBRT of $60 \mathrm{~s}$, but when the EBRT was decreased to $5 \mathrm{~s}$ the RE dropped to

$1523 \%$. This could indicate that the time that the pollutant was inside the capillaries was

16 not long enough to allow that the whole pollutant passes through the membrane,

17 indicating mass transport limitation, and only a little part of toluene was available for

18 the microorganisms. Anyway, it should be noted that despite the reduction in the

19 efficiency of system when EBRT was halved $(30 \mathrm{~s})$, the RE of $79 \%\left(\right.$ EC of $551 \mathrm{~g} \cdot \mathrm{m}^{-3} \cdot \mathrm{h}^{-}$

$20{ }^{1}$ or $0.2 \mathrm{~g} \cdot \mathrm{m}^{-2} \cdot \mathrm{h}^{-1}$ ) is still higher compared to classic biological configurations. In the

21 light of these results, a range between 30 and $60 \mathrm{~s}$ could be considered as the optimum

22 work range.

\subsubsection{Study of iso-octane abatement}

24 After proving the efficiency of the MBR in treating gas streams contaminated

25 with a common model compound (toluene), the performance of the bioreactor was 
1 evaluated using a more hydrophobic pollutant (iso-octane). Iso-octane is almost two

2 times more hydrophobic than toluene, apart of being a very recalcitrant pollutant due to

3 its quaternary carbon. The study was carried out for 22 days at EBRT of $60 \mathrm{~s}$ and an

4 average inlet concentration of $175 \mathrm{ppm}_{\mathrm{v}}$.

$5 \quad<$ FIGURA $4>$

6 In Fig 4, where the EC and the RE for iso-octane along 22 days of operation is

7 shown, it can be observed that the RE for iso-octane was slightly above $80 \%$ for the first

89 days, indicating a rapid acclimation of the biomass to the new pollutant. However,

9 from day 79 a continuous decrease of the removal efficiency was observed up to a

10 minimum of $38 \%$ on day 85 . Some authors have reported the complexity of the

11 biodegradation of this compound due to its chemical structure. In this sense, quaternary

12 carbon structures are known as highly recalcitrant. Actually, only one bacteria strain

13 (Mycobacterium austroafricanum) has been found to be capable to use iso-octane as

14 sole carbon and energy sources ${ }^{29}$. Nevertheless, Auffret et al. ${ }^{30}$ reported better

15 degradation rates of isooctane when this compound was supplied in a mixture, rather

16 than alone. For this reason, after day 85, a mixture of toluene and iso-octane was

17 introduced in order to verify whether iso-octane degradation is improved. As can be

18 seen, from the instant that toluene was reintroduced in the MBR, a gradual increase of

19 the removal efficiency (expressed as the total VOC's at the inlet) is reached, once again,

20 with values close to $80 \%$. The improvement in the RE\%, after toluene addition might

21 indicate that the microorganisms present in the biofilm were not capable to use the iso-

22 octane as a sole carbon source and they needed a co-substrate, in this case toluene. High

23 RE values observed during the first days might be explained due to the fact that the

24 microorganisms used the toluene retained and adsorbed on the membrane as a

25 secondary source of substrate. 
$1 \quad 3.2 .3$ Study of hexane performance

2 According to literature, unlike iso-octane, hexane can be used as sole carbon and

3 energy sources by many bacteria and fungi ${ }^{31-33}$; a compound that is normally used as 4 standard of highly hydrophobic pollutant. After iso-octane experiments, the MBR was

5 thoroughly washed and dried with clean air, in order to remove any compound adsorbed

6 on the membrane and to avoid further interactions. Then, the membrane was inoculated

7 again following the same procedure explained above and after the adaptation period, the

8 MBR was fed with a single hexane stream at EBRT of $60 \mathrm{~s}$ and an inlet concentration

9 ranged between 6 and $6000 \mathrm{ppm}_{\mathrm{v}}$. The bioreactor performance was again evaluated based on EC and RE\% values (Fig 5).

From the day 95 to 155 the maximum concentration that the system was capable to treat (EC) was studied. After this period an inlet concentration of $1000 \mathrm{ppm}_{\mathrm{v}}$ was fed again, moment at which the tests to determinate the relationship between the RE and EBRT were started (from day 156 to 174$)$.

As can be observed in Fig 5, where the EC and the RE of the system for hexane is represented, the maximum EC was $400 \mathrm{~g} \cdot \mathrm{m}^{-3} \cdot \mathrm{h}^{-1}\left(0.2 \mathrm{~g} \cdot \mathrm{m}^{-2} \cdot \mathrm{h}^{-1}\right)$ and the maximum values of RE obtained were close $50 \%$. However, when the relationship between EBRT and RE was studied an important decrease on the overall system performance at low EBRT was observed (from day 156 to 174). During this period, RE values lower than $10 \%$ were obtained. 
1 significantly lower in comparison to the EC previously observed for toluene. This

2 different behavior can be partially explained by the presence of a water layer. Due to the

3 liposolubility of hexane, the presence of water in the shell might produce a decrease in

4 the diffusion of the pollutant through the membrane. The EC obtained in the present

5 study are similar to those found in the literature. For instance, Zamir et al. ${ }^{34}$ found an

6 EC of $400 \mathrm{~g} \cdot \mathrm{m}^{-3} \cdot \mathrm{h}^{-1}$ at EBRT between $78-120 \mathrm{~s}$ when a biofilter inoculated with an

7 unidentified fungal consortium was used. The maximum EC obtained in the present

8 work is equal to the maximum EC reported previously. Therefore, the present system

9 allowed operating at low EBRT (meaning smaller reactor volume) and bacterial

10 consortium (more controllable and robust) instead of fungi. It is well-known that the use

11 of fungi instead of bacteria for degrading hexane normally achieves better performance

12 because fungi can directly transfer hexane from the gaseous phase into the aerial

13 structure of hyphae ${ }^{31}$. However, in this case the role of the membrane replaces this 14 advantage.

The relationship between RE and EBRT is plotted in Fig 6B. The maximum RE

of the system was close to $60 \%$ at the EBRT of 60 s but when the EBRT was reduced

17 from $60 \mathrm{~s}$ to $50 \mathrm{~s}$ the RE decreased drastically from $\sim 60 \%(60 \mathrm{~s})$ to $\sim 30 \%(50 \mathrm{~s})$. The

$18 \mathrm{RE}$ and the EC values obtained for hexane are very low in comparison to the values

19 observed previously, in the present work, for toluene. This means that despite the fact

20 that the membrane, is used here as a mass transfer vector, in an attempt to improve the

21 mass transfer of pollutants between the contaminated pas to the liquid phase (biofilm),

22 the pollutant hydrophobicity is a key parameter that can limits the effectiveness of the

23 system. Although the polymeric material of the membrane is used as a mass transfer

24 vector, the relatively low efficiency observed for the hexane, demonstrated that the

25 pollutant hydrophobicity is a key parameter when VOC are treated. Based on these 
1 results, the optimum EBRT working range to obtain a good abatement performance

2 when hexane was treated could be the EBRT ranged between 60 and $50 \mathrm{~s}$.

3 During the last days of the experiment, the system capability to treat hexane in 4 presence of other pollutants was studied. This part of the study was motivated for two 5 reasons. The first one is that a RE improvement of iso-octane was observed when it was 6 mixed with toluene and the second one was that most of the industrial VOC gaseous 7 emissions comprise more than a unique pollutant. Thus, a more realistic scenario for the 8 hexane degradation was studied. For this purpose, two different mixtures were used in 9 this stage, hexane-toluene and hexane-methanol. When toluene was introduced as a 10 second pollutant, no effect on the hexane removal RE\% was observed. Zhao et al. ${ }^{11}$ 11 reported similar results when a mixture of hexane and toluene was treated in a hollow 12 fiber MBR. On the other hand, when the second mixture (hexane-methanol) was used a 13 decreased in hexane RE\% was observed. According to literature, the addition of 14 methanol to other VOCs might have neutral, positive or negative effect depending on 15 the VOCs and their loading rates, nutrients availability, $\mathrm{pH}$, and temperature ${ }^{35}$. Under 16 the operating conditions used in the present study, the presence of methanol in the gas 17 stream had a negative effect on the hexane removal performance, a reduction of hexane 18 RE\% was observed. This reduction on the overall performance of hexane might be due 19 to the fact that methanol is a more biodegradable compound than hexane, so, the 20 microorganisms attached on the membrane had more preference to degrade methanol, 21 probably a competitive effect rather than a synergic effect occurred. These differences 22 suggested that further research is needed to understand the complex relationship 23 between co-substrates and the polypropylene capillary MBR behavior when complex 24 mixtures of compounds with different hydrophobic properties are treated. 
1 It is important to highlight that during the whole MBR performance the pressure 2 drop inside the membrane (gas side) was between 2-12 $\mathrm{mmH}_{2} \mathrm{O} / \mathrm{m}$, even when the 3 highest IL were fed. These values are lower than typically pressure drop reported by a 4 traditional biofiltration technique. Furthermore, no problems of bioclogging or 5 biofouling were observed. This is a valuable feature of MBR respect to biofiltres or 6 biotrickling filters, since biomass accumulation is one of the most critical problems that 7 need to be controlled for long-term operations. Thus, capillary MBR have the potential 8 to overcome one of the main problem of the traditional biotechniques. The excess of 9 biomass inside the bioreactor results in an increase of pressure drop, which ultimately 10 may lead to wash out of part of the biomass from the system or to force the 11 replacement of the support media ${ }^{3}$. The absence of bioclogging during the whole MBR 12 performance might be produced by the fact that the sheer stress of liquid flow was 13 enough to detach the biofilm overgrow and eliminated through the purge. Thus, a thin 14 biofilm was established on the membrane surface avoiding bioclogging and channeling 15 but with enough thickness to abate satisfactorily hydrophobic pollutants.

\section{CONCLUSIONS}

Results illustrate the effective abatement of different VOC's with a commercial microporous membrane adapted for waste gas treatment. Toluene was removed with high efficiencies (80-99\%) with a maximum EC of $1309 \mathrm{~g} \cdot \mathrm{m}^{-3} \cdot \mathrm{h}^{-1}$, which improves previous results for biological processes. For iso-octane, a poorer RE was observed when it was fed alone as well as for hexane. Low and constant pressure drop monitored during the whole experiment indicates the high stability and robustness of MBR overcoming one of the main limitation of classic biofiltration. The main application of

24 this module is the treatment of moderate-small flows with high loading rates. 


\section{ACKNOWLEDGEMENTS}

2

3

4

5

6

7

8

9

10

11

12

13

This work was supported by Ministerio de Economía y Competitividad (Spain) (CTQ2015-69802-C2-2-R, 2016). The authors would like to thank the financial support from Ecología Técnica, S.A. The authors gratefully acknowledge Jordi Flores and technical lab staff for his help in the tests.

\section{REFERENCES}

1. Agency(EPA), U.S.E.P. 2016. The original list of hazardous air (2016) [WWW

Document]. Orig. List Hazard. air Pollut. URL https://www3.epa.gov/ttn/atw/188polls.htmL (accessed 3.11.16) .

2. Lebrero R, Rodríguez E, Estrada JM, García-Encina PA and Muñoz R, Odor abatement in biotrickling filters: Effect of the EBRT on methyl mercaptan and hydrophobic VOCs removal. Bioresour Technol 109: 38-45 (2012) doi:10.1016/j.biortech.2012.01.052

3. Dorado AD, Baeza JA., Lafuente, J, Gabriel D and Gamisans X, Biomass accumulation in a biofilter treating toluene at high loads - Part 1: Experimental performance from inoculation to clogging. Chem Eng J 209: 661-669 (2012). doi:10.1016/j.cej.2012.08.018

4. Aizpuru A, Dunat B, Christen P, Auria R, García-Peña I and Revah S, Fungal Biofiltration of Toluene on Ceramic Rings. J Environ Eng 131: 396-402 (2005). doi:10.1061/(ASCE)0733-9372(2005)131:3(396)

5. Attaway H, Gooding $\mathrm{CH}$ and Schmidt MG, Biodegradation of BTEX vapors in a silicone membrane bioreactor system. J Ind Microbiol Biotechnol 26: 316-325 (2001). doi:10.1038/sj/jim/7000137

24 7774-7782 (2009). doi:10.1128/AEM.01117-09 
1 6. Fitch M, Neeman J and England E, Mass transfer and benzene removal from air using

2 latex rubber tubing and a hollow-fiber membrane module. Appl. Biochem.

$3 \quad$ Biotechnol. 104: 199-214 (2003)

4 7. Muñoz R, Gan EIHH, Hernández M and Quijano G, Hexane biodegradation in two-

5 liquid phase bioreactors: High-performance operation based on the use of

$6 \quad$ hydrophobic biomass. Biochem Eng J 70: 9-16 (2013)

$7 \quad$ doi:10.1016/j.bej.2012.09.009

8 8. Álvarez-Hornos FJ, Volckaert D, Heynderickx PM and Van Langenhove H,

9 Performance of a composite membrane bioreactor for the removal of ethyl acetate

10 from waste air. Bioresour Technol 102: 8893-8 (2011).

11 doi:10.1016/j.biortech.2011.06.064

12 9. Kraakman NJR, Rocha-Rios J and Van Loosdrecht, MCM, Review of mass transfer

13 aspects for biological gas treatment. Appl Microbiol Biotechno. 91: 873-886 (2011) doi:10.1007/s00253-011-3365-5

10. Dingemans, M., Dewulf, J., Kumar, A. and Van Langenhove, H. Solubility of

volatile organic compounds in polymers: Effect of polymer type and processing. $J$.

17 Membr. Sci., 312: 107-114 (2008)

11. Zhao K, Xiu G, Xu L, Zhang D, Zhang, X and Deshusses M A, Biological treatment of mixtures of toluene and n-hexane vapours in a hollow fibre membrane bioreactor Environ Technol 32: 617-623 (2011) doi:10.1080/09593330.2010.507634

22 12. Sempere F, Gabaldón C, Martínez-Soria V, Penya-roja JM and Álvarez-Hornos FJ, 23 Evaluation of a combined activated carbon prefilter and biotrickling filter system 
1 treating variable ethanol and ethyl acetate gaseous emissions. Eng Life Sci 9: $317-$

2323 (2009) doi:10.1002/elsc.200900011

3 13. Juang RS, Lin SH and Yang MC, Mass transfer analysis on air stripping of VOCs

4 from water in microporous hollow fibers. J Memb Sci 255: 79-87(2005)

$5 \quad$ doi:10.1016/j.memsci.2005.01.022

6 14. Mahmud H, Kumar A, Narbaitz RM and Matsuura, T, Mass transport in the membrane air-stripping process using microporous polypropylene hollow fibers: Effect of toluene in aqueous feed. J Memb Sci 209: 207-219 (2002) doi:10.1016/S0376-7388(02)00320-4

15. Kumar A, Dewulf J and Van Langenhove H, Membrane-based biological waste gas treatment. Chem Eng $J$ 136: 82-91 (2008) doi:10.1016/j.cej.2007.06.006

16. Volckaert D, Wuytens $\mathrm{S}$ and Van Langenhove $\mathrm{H}$, Two phase partitioning membrane bioreactor: A novel biotechnique for the removal of dimethyl sulphide, n-hexane and toluene from waste air. Chem Eng J 256: 160-168 (2014) doi:10.1016/j.cej.2014.06.033

17. Wang Z, Xiu G, Wu X, Wang L, Cai J and Zhang D, Biodegradation of xylene mixture from artificial simulated waste gases by capillary membrane bioreactors. Chem. Eng. J. 229: 508-514 (2013) doi:10.1016/j.cej.2013.05.001

18. Reij MW, Keurentjes JT and Hartmans, S, Membrane bioreactors for waste gas treatment. J Biotechnol 59: 155-167 (1998) doi:10.1016/S0168-1656(97)00169-7

19. Fortuny M, Baeza JA, Gamisans X, Casas C, Lafuente J, Deshusses MA and Gabriel D, Biological sweetening of energy gases mimics in biotrickling filters. Chemosphere 71: 10-17 (2008) doi:10.1016/j.chemosphere.2007.10.072 
1 20. Dorado AD, Lafuente J, Gabriel D and Gamisans, X, The role of water in the

2 performance of biofilters: parameterization of pressure drop and sorption capacities

3 for common packing materials. J. Hazard. Mater. 180: 693-702 (2010)

$4 \quad$ doi:10.1016/j.jhazmat.2010.04.093

5 21. Giles CH, MacEwan TH, Nakhwa SN and Smith D, Studies in adsorption. Part XI.

6 A system of classification of solution adsorption isotherms, and its use in diagnosis

7 of adsorption mechanisms and in measurement of specific surface areas of solids.

$8 \quad$ J. Chem. Soc. 846: 3973-3993 (1960) doi:10.1039/jr9600003973

9 22. Dorado AD, Lafuente J, Gabriel D, Gamisans X,. Interaction between sorption and

24. Rodriguez G, Dorado AD, Bonsfills A, Sanahuja R, Gabriel D and Gamisans X, Optimization of oxygen transfer through venturi-based systems applied to the biological sweetening of biogas. J Chem Technol Biotechnol 87: 854-860 (2012) doi:10.1002/jctb.3731

25. Brindle K and Stephenson T, Nitrification in a bubbleless oxygen mass transfer membrane bioreactor. Water Sci Technol 34: 261-267 (1996) doi:10.1016/S02731223(96)00813-X

26. Kumar A, Hille-Reichel A, Horn H, Dewulf J, Lens P and Van Langenhove, H, Oxygen transport within the biofilm matrix of a membrane biofilm reactor treating gaseous toluene. J Chem Technol Biotechnol 87: 751-757 (2012) 
doi: $10.1002 /$ jctb. 3800

2 27. Dorado AD, Baeza JA, Lafuente J, Gabriel D and Gamisans X, Biomass

3

4 performance from inoculation to clogging. Chem Eng J 209: 661-669 (2012). doi:10.1016/j.cej.2012.08.018

28. Zilli M, Del Borghi A and Converti A, Toluene vapour removal in a laboratory-

29. Solano-Serena F, Marchal R, Heiss S and Vandecasteele JP, Degradation of isooctane by Mycobacterium austroafricanum IFP 2173: Growth and catabolic pathway. J Appl Microbiol 97: 629-639 (2004) doi:10.1111/j.13652672.2004.02344.x

30. Auffret M, Labbé D, Thouand G, Greer, CW and Fayolle-Guichard F, Degradation of a mixture of hydrocarbons, gasoline, and diesel oil additives by Rhodococcus aetherivorans and Rhodococcus wratislaviensis. Appl Environ Microbiol 75, 77747782 (2009) doi:10,1128/AEM.01117-09

31.Lee EH, Kim J, Cho KS, Ahn YG and Hwang GS, Degradation of hexane and other recalcitrant hydrocarbons by a novel isolate, Rhodococcus sp. EH831. Environ Sci Pollut Res 17: 64-77 (2010) doi:10.1007/s11356-009-0238-x

32. Hernández M, Quijano G, Thalasso F, Daugulis AJ, Villaverde S and Muñoz R, A comparative study of solid and liquid non-aqueous phases for the biodegradation of hexane in two-phase partitioning bioreactors. Biotechnol Bioeng 106: 731-740 (2010) doi:10.1002/bit.22748 
1 33. Spigno G, Pagella C, Fumi MD, Molteni R and De Faveri DM, VOCs removal from

2 waste gases: Gas-phase bioreactor for the abatement of hexane by Aspergillus

3 niger. Chem Eng Sci 58: 739-746 (2003) doi:10.1016/S0009-2509(02)00603-6

4 34. Zamir SM, Ferdowsi M and Halladj R, Effects of loading type and temperature on

5 performance, transient operation, and kinetics of n-hexane vapor removal in a

6 biofilter. Water Air Soil Pollut 225: $1825-1830$ (2014) doi:10.1007/s11270-013-

7 $1825-5$

8 35. Zehraoui A, Hassan AA and Sorial GA, Effect of methanol on the biofiltration of n-

9 hexane. J Hazard Mater 15: 219-220, 176-182 (2012) doi:10.1016/j.jhazmat.2012.03.075

11

12 Supplementary material

13 
1

2

3

4

5

6

7

8

9

10

11

12

13

14

15

16

17

18

19

20

21

22

23

24

25

26

27

28

29

30

31

32

33

34

35

36

37

38

39

40

41

42

43

44

45

46

47

48

49

50

51

52

53

54

55

56

57

58

59

60

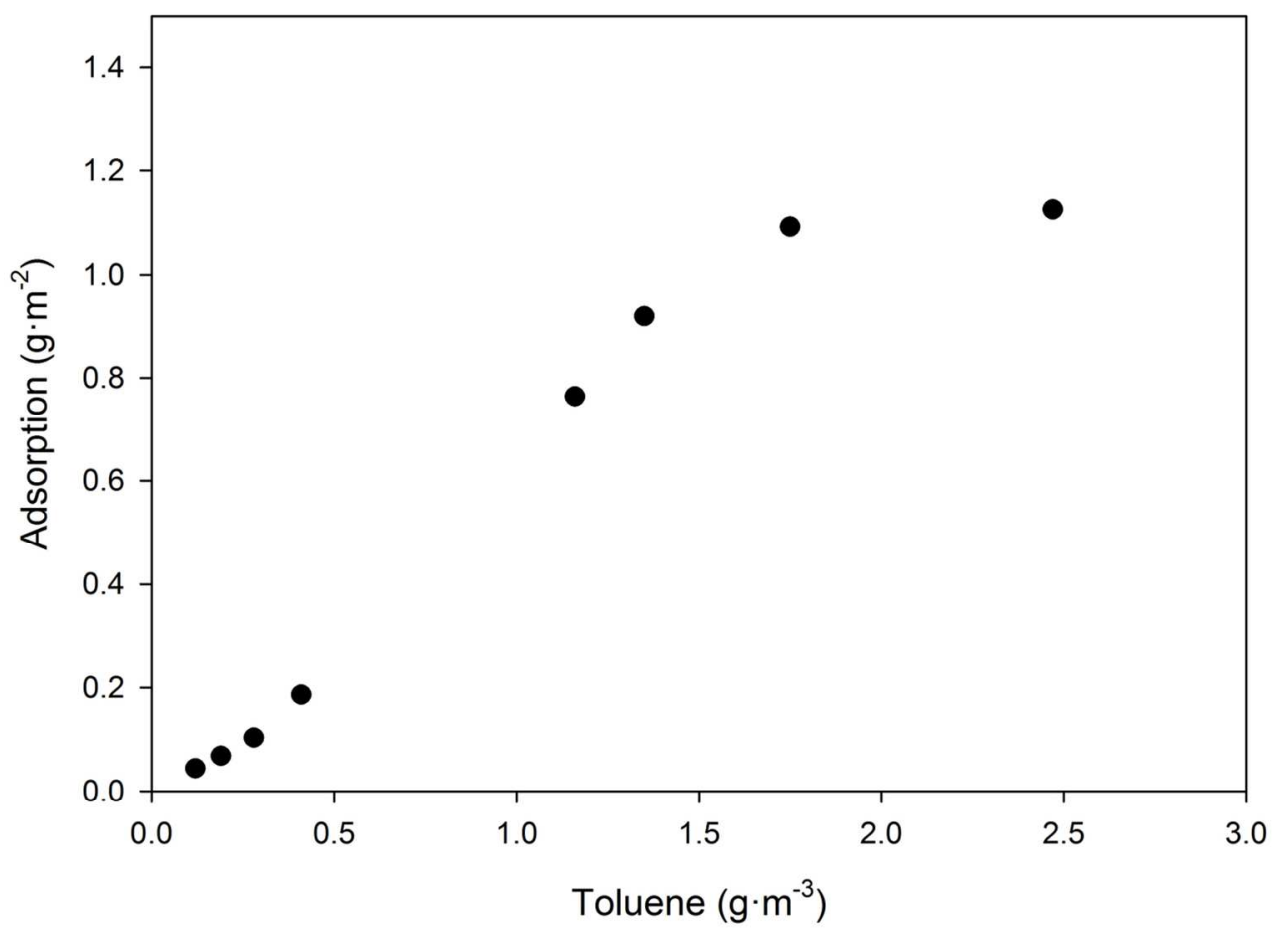

Sorption capacity of toluene $(\bullet)$ in the membrane $117 \times 92 \mathrm{~mm}(300 \times 300$ DPI $)$ 


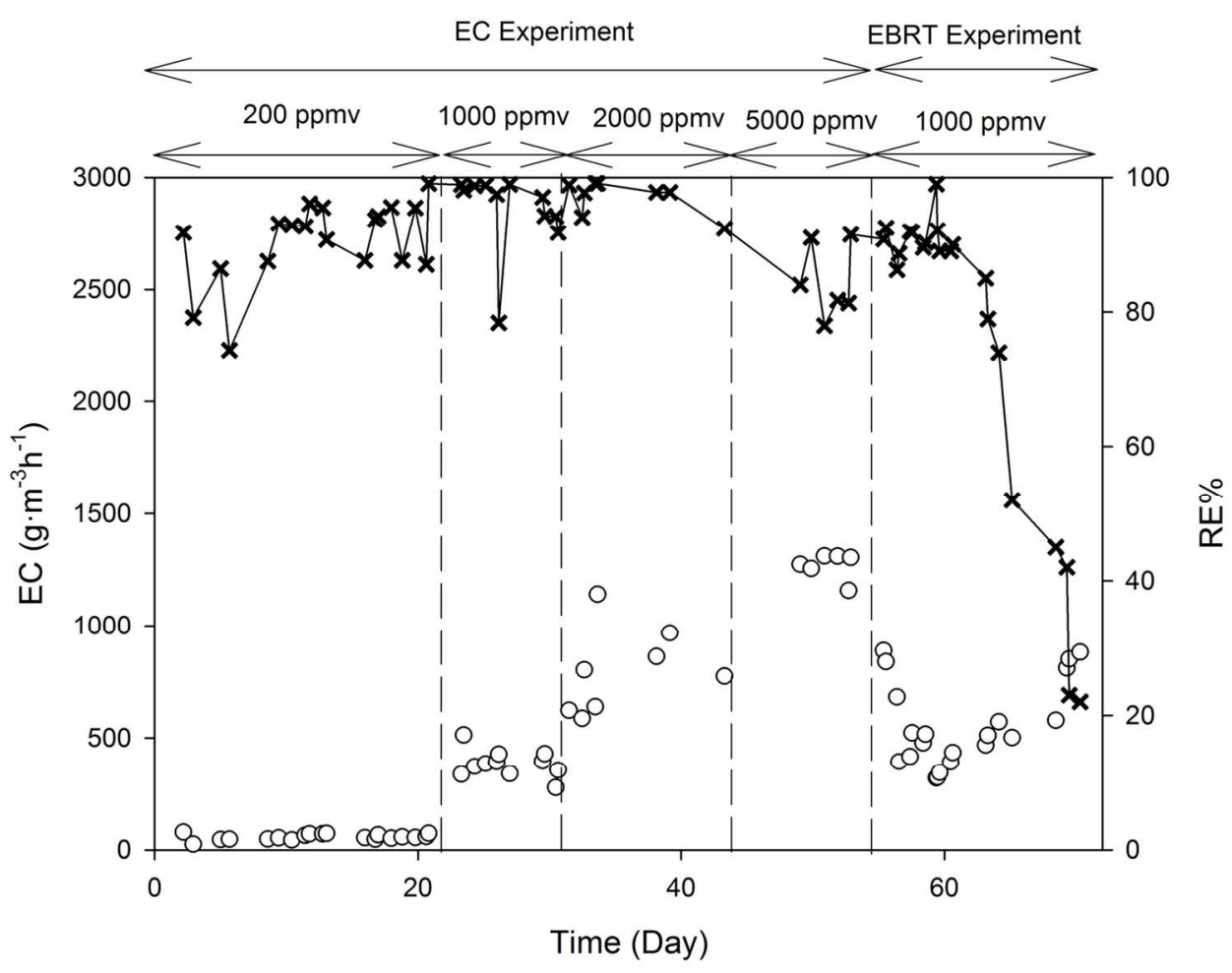

Evolution of the RE ( $x$, secondary axis) and EC ( 0 ) of toluene $141 \times 119 \mathrm{~mm}(300 \times 300$ DPI $)$ 

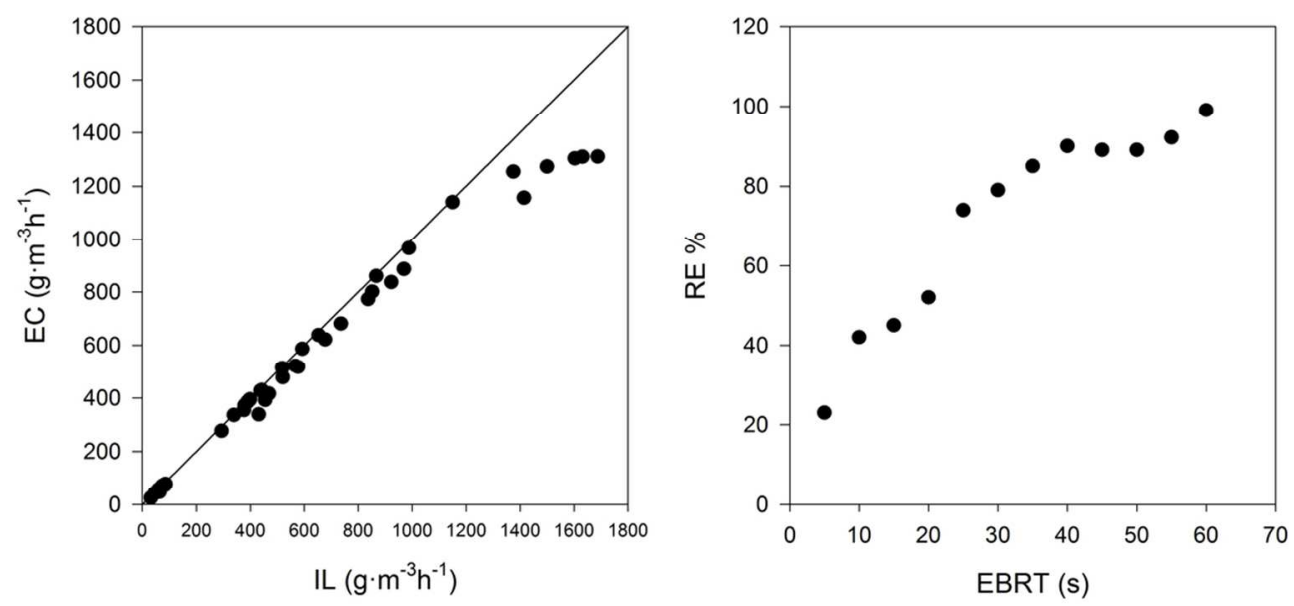

A; Toluene variation of EC $(\bullet)$ with IL. B; Toluene relationship between EBRT and $\operatorname{RE}(\bullet)$ $96 \times 46 \mathrm{~mm}(300 \times 300 \mathrm{DPI})$ 


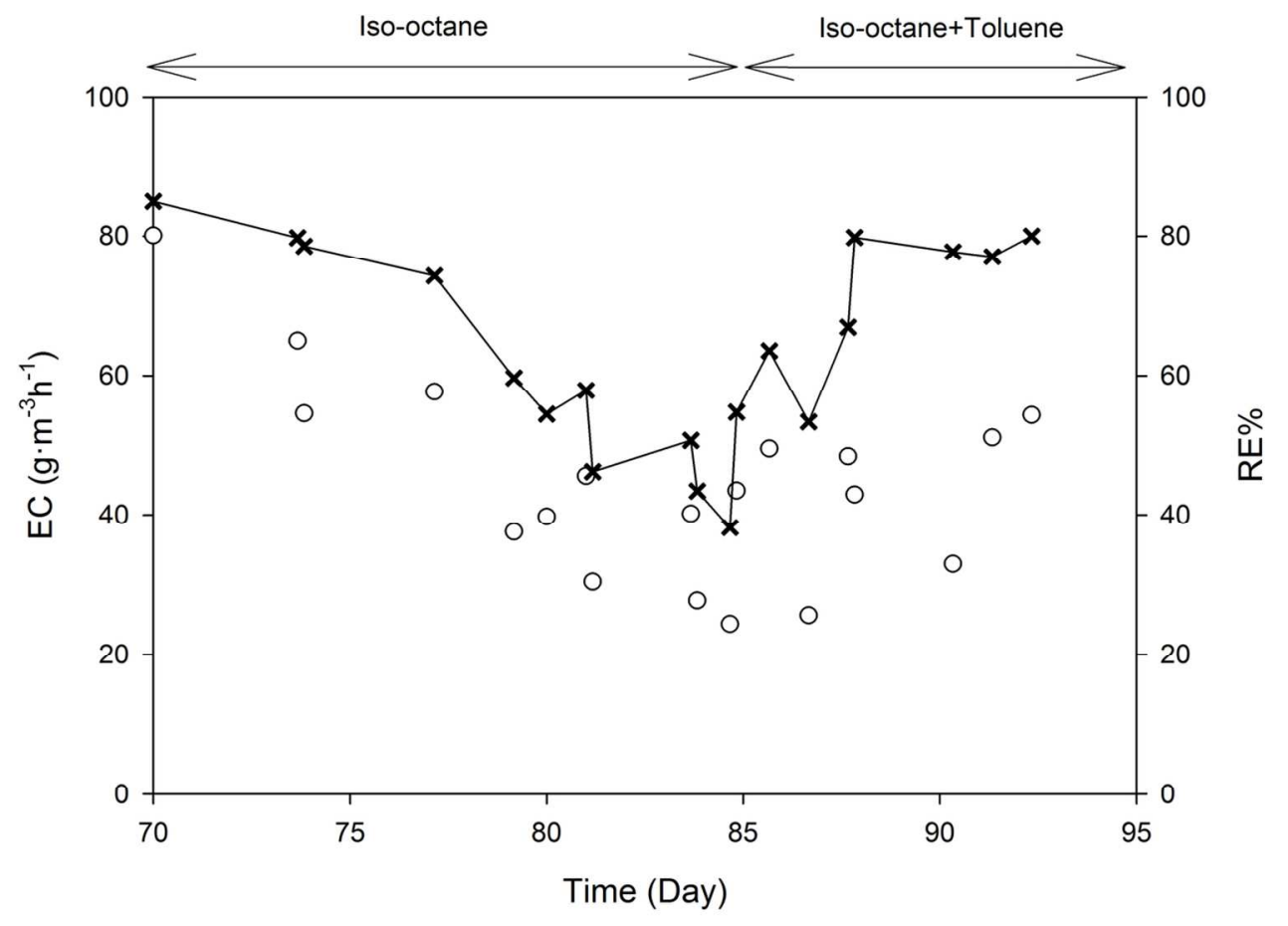

Evolution of the RE ( $x$, secondary axis) and EC (o) of iso-octane and iso-octane/toluene mixtures

$117 \times 84 \mathrm{~mm}(300 \times 300$ DPI $)$ 


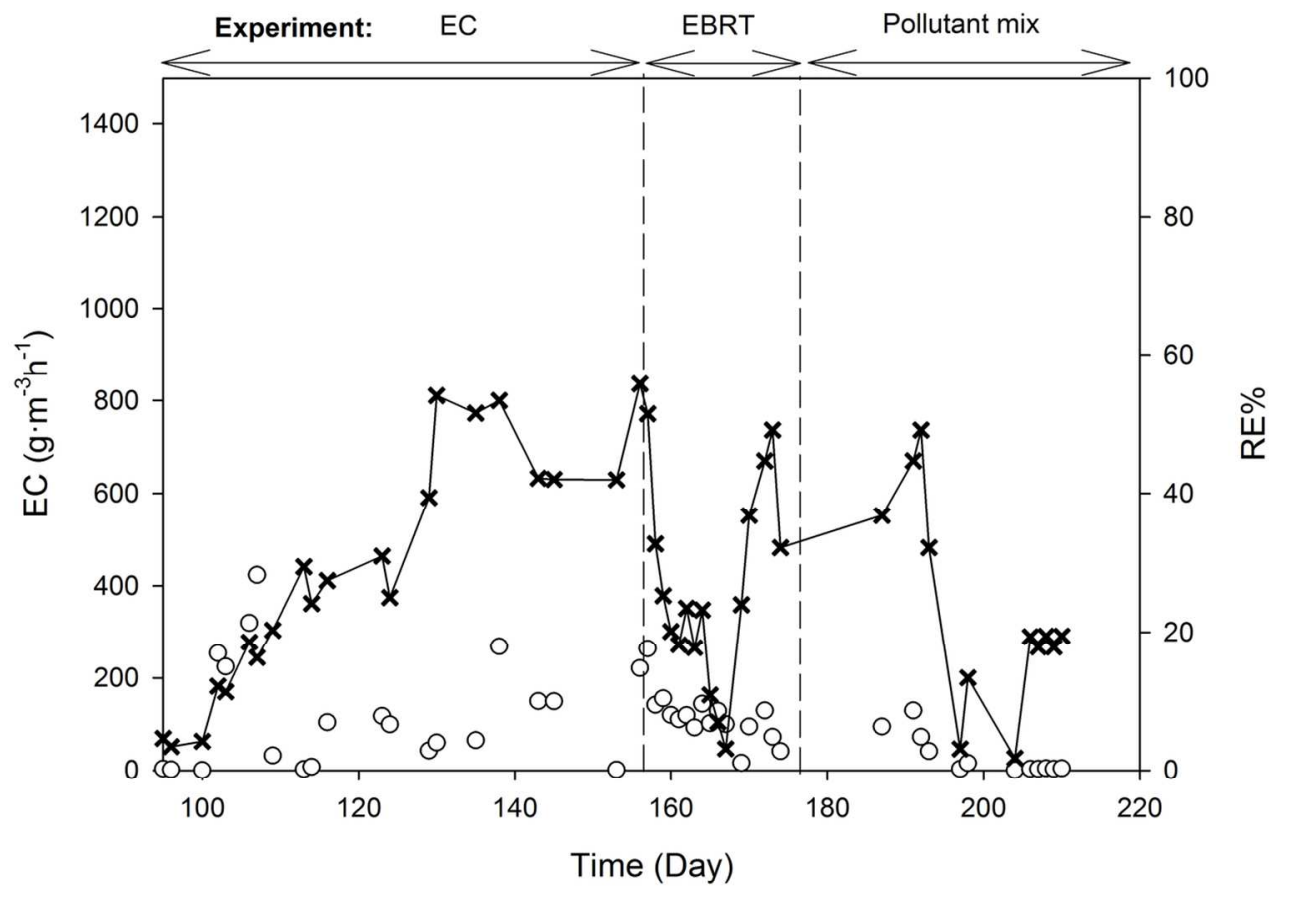

EC ( $\circ$ ) and RE ( $x$, secondary axis) during hexane and hexane/toluene and hexane/methanol mixtures tests $120 \times 87 \mathrm{~mm}(300 \times 300$ DPI $)$ 

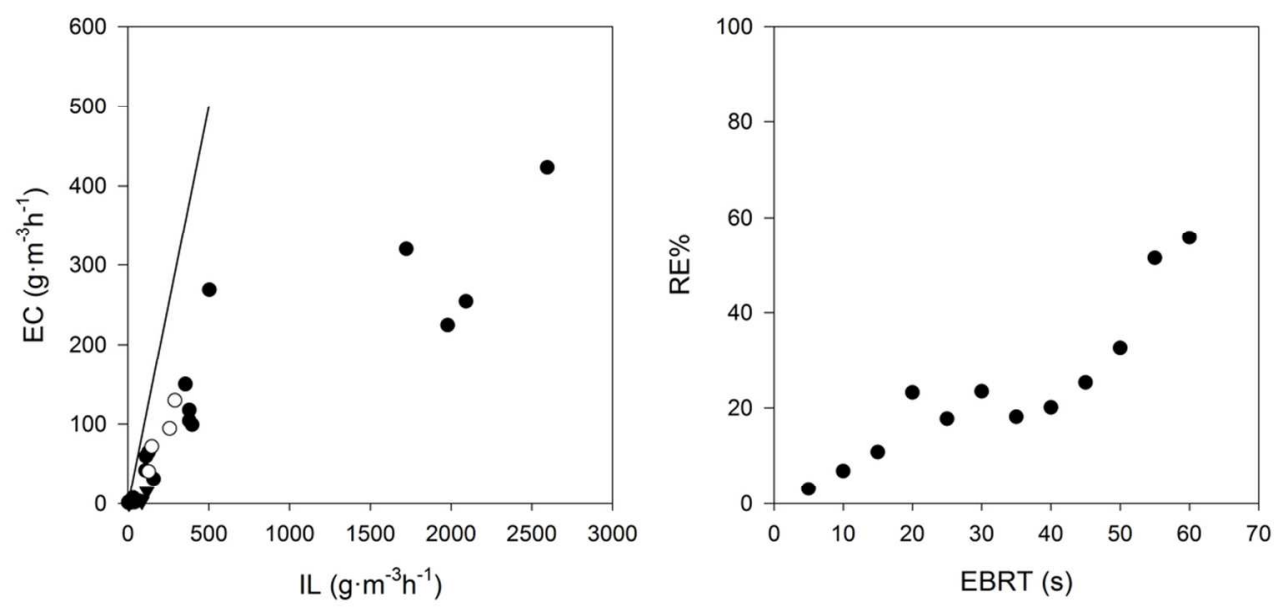

A; Hexane variation of EC with IL, $(\bullet)$ hexane, (o) hexane+toluene, $(\mathbf{v})$ hexane+methanol. $\mathrm{B}$; Hexane relationship between EBRT and RE $(\bullet)$

$97 \times 47 m m(300 \times 300$ DPI $)$ 


\begin{tabular}{ccccc}
\hline Stage & Pollutant & Days & EBRT & Experiment \\
\hline \multirow{2}{*}{ Stage 1 } & Toluene & $2-50$ & $60 \mathrm{~s}$ & Maximum EC \\
& Toluene & $60-70$ & $5-60 \mathrm{~s}$ & EBRT \\
\hline \multirow{2}{*}{ Stage 2 } & Iso-octane & $71-84$ & $60 \mathrm{~s}$ & - \\
& Iso-octane/Toluene & $85-92$ & $60 \mathrm{~s}$ & Co-metabolism \\
\hline \multirow{2}{*}{ Stage 3 } & Hexane & $95-154$ & $60 \mathrm{~s}$ & Maximum EC \\
& Hexane/Toluene & $176-185$ & $60 \mathrm{~s}$ & Pollutant mix \\
& Hexane/Methanol & $186-190$ & $60 \mathrm{~s}$ & Pollutant mix \\
\hline
\end{tabular}

Table I Summarize of operation conditions during the 3 stages 


\section{Supplementary material}

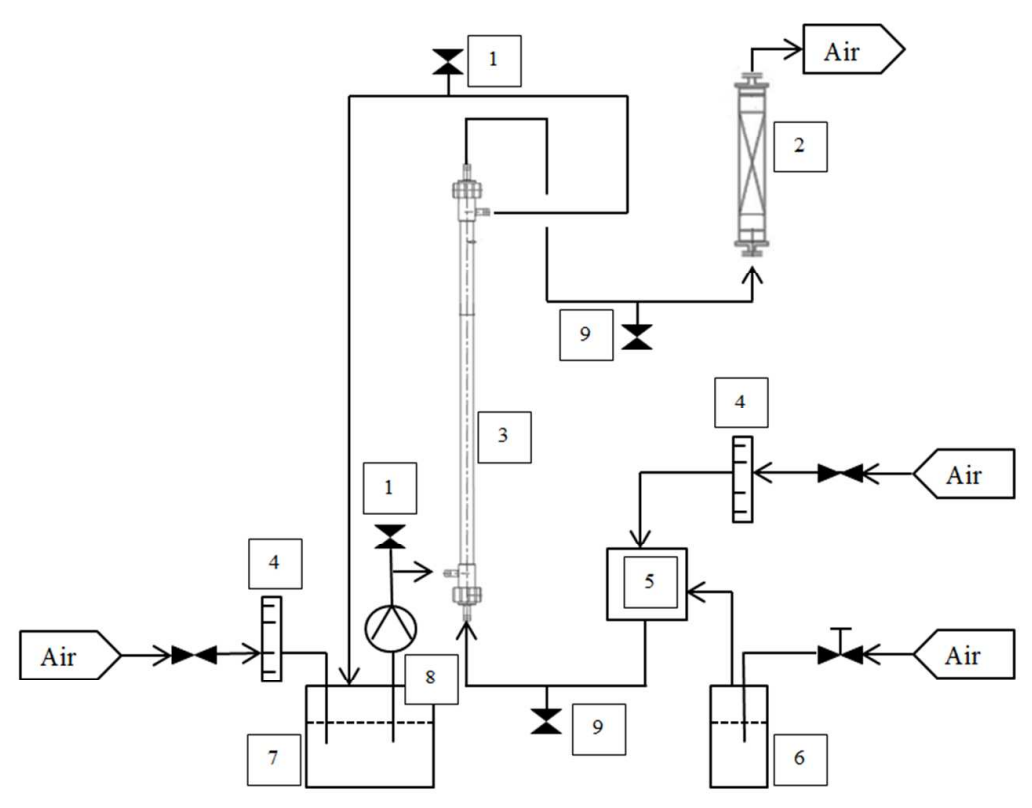

Figure A.1: Schematic of the lab scale plant. 1: Liquid sampling port, 2: Carbon filter, 3: Membrane bioreactor, 4: Flowmeter, 5: Mixer chamber, 6: VOC's bottle, 7: Nutrients tank, 8: Peristaltic pump, 9: Gas sampling port 